\title{
Factors influencing students' selection of universities: The case of Oman
}

\author{
Abdelghani Echchabi ${ }^{*}$, SalimAl-Hajri ${ }^{2}$ \\ ${ }^{1}$ Woosong University, South Korea \\ ${ }^{2} A$ 'Sharqiyah University, Oman
}

A R T I C L E I N F O

Article history:

Received 6 February 2018

Received in revised

form

7 March 2018

Accepted 16 April

2018

Available online 24

May 2018

Oman, University,

College, Students.

\begin{abstract}
A B S T R A C T
The main purpose of the study was to examine the factors that mostly influence students' selection of the universities where they enrolled, in the Omani context. The study used mean values to rank the factors based on the students' responses. The study covered a sample of 384 respondents from various Omani regions and used the mean value to examine the factors that influence students' selection of their respective universities. The findings revealed that the main factor for university selection is the university reputation, followed by completion time, academic quality, as well as the academic staff qualifications. These findings have significant contributions to the Omani universities, as well as universities in similar contexts. Particularly, it provides the universities with insights on the main dimensions and characteristics to emphasize in order to enhance their overall performance.
\end{abstract}

Copyright (C) Universitas Pendidikan Ganesha. All rights reserved.

\section{Introduction}

Throughout history, education has played a major role in the development and advance of nations worldwide. Whether informal education in an early era, or the current formal education, the higher education has been strongly linked to economic development and growth of nations but rather in a complex manner (Kruss, McGrath, Peterson and Gastrow, 2015). This is because many other related factors need to be considered, including geography, economic sectors, available human skills and other resources, education systems, network of companies in the country, etc.

Unfortunately, the rate of school dropout in many countries is relatively high. This is very likely to hinder the proper development aspirations of these countries. It is noteworthy for instance that an average of 7,000 students per year drop out from the degree courses in Oman, in a country with a total population of less than 5 million. This high rate of school dropout raises serious questions on the factors that cause it, though considerable efforts are deployed by the government to promote higher education. This includes scholarships and other forms of financial assistance provided to local students, the establishment of high standard universities in most of the regions in the country, the establishment of enhancement centers within the universities to maintain an acceptable level of students' performance, providing transport means for students living relatively far from the campus, etc.

It is rather obvious that the issue of school dropout, considered in the case of Oman, needs a comprehensive and thorough study to be properly understood and solved overtime. However, it is believed that identifying the factors that lead students to opt for higher education and choose their respective universities would rather help the latter in attracting and retaining students till they complete their higher education. Hence, the objective of the current study is to examine and identify the main factors that influence the students' selection of their respective universities. For this matter, a questionnaire is randomly distributed to university students in many regions of Oman in an effort to cover as many regions of the country as possible. 
It is noteworthy that the findings of the current study will bring about significant contributions. Firstly, it will provide insights on the main dimensions to be emphasized in order to avoid schools' dropout, as well as increasing students' enrolment in Omani universities. Secondly, the findings will guide the Omani universities in the process of recruiting and retaining students, as well as helping the students enroll in the most suitable program of their choice. To the best of the authors' knowledge no similar study has been conducted so far. Hence, the current study will have a great theoretical contribution in the area of university selection as well.

The study of university's selection criteria by students is a very vital aspect of the education sector, which has significant impacts on the education institutions as well as all their stakeholders. This area has been widely examined both in theoretical and empirical studies.

Mehboob, Shah and Bhutto (2012) investigated the factors affecting students' enrollment decision in Pakistani universities. The study covered a sample of 251 students from higher education institutions in Pakistan. The findings demonstrated that three factors which were further categorized into eleven sub factors were the main selection criteria for the students. These include internal factors (aspiration, aptitude, and career), external factors (courses, cost, location, reputation, promotion, and facilities) and social factors (parents, friends and teachers).

Dahari and Abduh (2011) attempted to determine the factors influencing international postgraduate students in selecting universities in Malaysia. The authors covered a sample of 135 respondents and applied the analytic hierarchy process (AHP) to determine the importance of each factor for the respondents. The findings indicated that the programs offered are the main factor which influences overall international students' choice to opt for a postgraduate study in Malaysian universities. Furthermore, there were some significant differences between students from Asian and Western countries in ranking the importance of each factor.

In a similar context, Misran, Abd. Aziz, Arsad, Hussain, Wan Zaki and Sahuri (2012) examined the students' decision in selecting specific university and program of study at undergraduate level in Malaysia. The authors focused specifically on Negeri Sembilan and Malacca regions, and found that factors such as suitability, interest, and career opportunities are the main reasons that led them to select their universities.

In the same context, Ramalu, Abu Bakar and Nijar (2013) investigated the factors that determine students' preferences in selecting higher learning institutions in Malaysia. The survey questionnaire was distributed to 1993 respondents from various institutions, and revealed that the main factors that determine students' preferences in selecting higher learning institutions are quality of education, campus facilities and atmosphere, external and financial factors, and advertisement and publicity.

In a different context, Jafari and Aliesmaili (2013) studied the factors that influence the preuniversity students' selection of universities in the Northern region of Iran. Findings showed that economic factors, university related factors, personal factors, and social factors influence student's choice of university respectively.

In another context, Agrey and Lampadan (2014) examined the factors that contribute to the students' selection of universities in Thailand, focusing on a sample of 261 respondents from the central region of the country. The findings revealed that the selection criteria include support systems, both physical and non-physical; secondly, learning environment and job prospects; thirdly having good sporting facilities; fourthly, a strong student life program and activities, and finally a safe and friendlyenvironment.

In a different study, Winn, Leach, Erwin and Benedict (2014) investigated the factors that determine Masters Students' selection of programs in the South West United States. Their findings indicated that the students selected their current university and programs based primarily on the course delivery methods (with hybrid courses mostly preferred) as well as the convenience that the programs offer. Furthermore, the participants perceived online advertising as well as face to face contact with the university representatives as the main recruitment strategies.

In a different study, Maniu and Maniu (2014) attempted to identify the main university selection criteria, through a comprehensive review of literature. They found that institutional reputation, cost,employment opportunities, parents' influence, educational offer, and location are the main factors that influence students' selection of universities.

In summary, the above studies have been conducted in several settings, and focused on different factors. These studies have provided a comprehensive set of factors that are considered and tested in the current study. 


\section{Method}

The targeted population in the study is the university students in Oman from all levels, i.e. Diploma, Bachelor, Masters and Ph.D. The study attempted to cover as many regions of the country as possible depending on the accessibility. Accordingly, a sample sizeof384 respondents was estimated using the following formula:

$$
S S=\frac{\left(z^{2}\right) \times(p) \times(1-p)}{\mathrm{c}^{2}}
$$

Where, SS refers to the sample size, $\mathrm{Z}$ is the $\mathrm{Z}$-value (estimated at 1.96 in this case), $\mathrm{P}$ is the percentage of the population (estimated at 0.5 in this case), and $\mathrm{C}$ is the confidence interval (estimated at 0.04 in this case).

A survey questionnaire was specifically designed to collect information about the factors that lead students to select a specific university based on earlier studies (e.g. Misran, Abd. Aziz, Arsad, Hussain, Wan Zaki and Sahuri, 2012; Ramalu, Abu Bakar, and Niar, 2013; Dahari and Abduh, 2011; Agrey and Lampadan, 2014; Winn, Leach, Erwin and benedict, 2014). For measuring this information, 5 points-Likert type scaling was used $(1=$ Strongly disagree and $5=$ Strongly agree). 21 items derived from the above literature were listed in this section. The second section of the questionnaire explored information about respondents' profile, i.e. gender, age, education level, etc. The questionnaire was made in English and was subsequently translated into Arabic language and distributed in both versions.

The collected data were subsequently analyzed using simple descriptive statistics as well as Friedman tests to rank the derived factors. The choice of this technique was inspired from Hair, Black, Babin and Anderson (2010) as well as from similar studies conducted in this area. It is worth mentioning that the analysis was done through SPSS 18.

\section{Discussion}

The profile analysis in Table 1 indicates that nearly 84 per cent of the respondents are female, while more than 16 per cent of the respondents are male. In terms of age distribution, about 44 per cent of the respondents are 20 to 21 years old, about 43 per cent of the respondents are 22 to 23 years old, about 7 per cent are 18 to 19 years old, while nearly7 per cent are 24 years old or above. Finally, in terms of education levels distribution, nearly 54 per cent of the respondents intends to obtain a Diploma, about 42 per cent of the respondents intend to obtain a Bachelor's degree, while nearly 5 per cent intend to obtain a Postgraduate degree.

Table 1: Profile analysis

\begin{tabular}{|l|l|l|}
\hline Demographics & Categories & Percentage \\
\hline Gender & Male & 16.3 \\
\cline { 2 - 3 } & Female & 83.7 \\
\hline \multirow{4}{*}{ Age } & Less than 18 years & - \\
\cline { 2 - 3 } & 18 to 19 years & 6.7 \\
\cline { 2 - 3 } & 20 to 21 years & 43.7 \\
\cline { 2 - 3 } & 22 to 23 years & 42.7 \\
\cline { 2 - 3 } & 24 years old and above & 6.9 \\
\hline \multirow{5}{*}{ Intended degree } & Diploma & 53.5 \\
\cline { 2 - 3 } & Bachelor's degree & 41.6 \\
\cline { 2 - 3 } & Postgraduate degrees & 4.9 \\
\hline
\end{tabular}

On the other hand, Table 2 provides the mean and standard deviation values for the university selection factors covered in the study, as well as the ranking based on the mean values. The results indicate that the most important factor influencing students' selection is the university reputation and image among peer students with a mean value of 4.576. This finding is in line with earlier studies such as Mehboob et al. (2012) and Maniu and Maniu 2014). And this is particularly valid in the case of Oman where there is high competition between fresh graduates to obtain a suitable job in a market that has not 
been offering much jobs recently, and where fresh graduates would wait 1 year in average before getting a job.

This is followed by the completion time with a mean value of 4.477, which is usually a very significant factor for students to identify universities where they would be studying. This is in line with the findings of Jafari and Aliesmaili (2013). The third most important factor for students is the academic quality, which generally reflects how the education institutions support the students' learning. This factor carries a mean value of 4.369 and it is in line with Ramalu et al. (2013).

This is followed by the academic staff qualifications and experiences with a mean value of 4.36. It is noteworthy that Omani Universities have been very successful in attracting experienced and highly qualified academic staff from different parts of the globe. And this has brought a great added value to the students by having different perspectives on current issues and getting exposure to many different cultures.

It is noteworthy at this level that the students usually refer to their high school teachers for advice regarding which university to join (a mean value of 4.297). Hence, it will be very important for universities to conduct awareness campaigns at local schools and keep the schools' management and teaching staff updated about the latest developments at the universities, which might include new programs offered, new major policies, new appointment of management staff, etc.

The sixth most important factor for the students is the type of programs offered with a mean value of 4.252. This is in line with Dahari and Abduh (2011), Misran et al. (2012), and Winn et al. (2014). It is noteworthy that new programs are developed first through a proposal submitted by the respective universities to the Ministry of Higher Education (MOHE) in Oman, where the latter studies the proposal and provides a decision mainly by acceptance or rejection. However, there are many cases, where the MOHE itself recommends universities to submit a proposal to launch a program selected by MOHE after a comprehensive study of the market needs. Hence, universities in Oman would usually have programs that fit with their strategic plans, but also manage as much as possible to incorporate the MOHE trends.

The seventh most important factor for students is the accommodation with a mean value of 4.216. This particularly valid in the case of Oman, as in most cases, majority of the university students are female. Hence their families would want to ensure that they are well settled, and that they have access to transport back and forth to the university.

It is noteworthy also that the students refer to their friends and family for advice in selecting their respective universities. Thus, it might be of great significance to conduct collective advertisement campaigns where the attendants would be both the prospective students and their families.

This is followed by the university environment with a mean value of 4.162 and possibility of financial assistance with a mean value of 4.126. It is noteworthy here that MOHE is very active in providing scholarships to local students. Besides, the universities also provide considerable amounts of financial assistantship to students. Hence, students would generally prefer universities that provide additional financial assistance. This is in line with Ramalu et al. (2013).

Next in line are the facilities (mean value of 4.045) and the possible contact with university representatives (mean value of 4) that usually has a significant impact on the students' decisions. These are followed by the tuition fees with a mean value of 3.99. It is noteworthy that the tuition fees do not seem to be particularly important for the respondents as most of them are provided with MOHE scholarships which renders the tuition fees level not really important for the students.

This is followed by the universities entry requirement with a mean value of 3.98 . This mainly refers to the minimum high school grade accepted by the University for Admission. This differs from one university to another and it also differs across programs.

However, there are factors that seem to have less importance for students' choice, including contact with program representatives (mean value of 3.783), website advertisement (mean value of 3.648), advertisement in social media (mean value of 3.540), campus size (mean value of 3.504), university location (mean value of 3.459), social activities (mean value of 3.342), and advertisement in printed sources (mean value of 3.189 ). 
Table 2: Summary statistics

\begin{tabular}{|l|r|r|r|}
\hline & Mean & Std. Deviation & Rank \\
\hline University Reputation & 4.5766 & .91998 & 1 \\
\hline Completion time & 4.4775 & .87227 & 2 \\
\hline Academic Quality & 4.3694 & .85203 & 3 \\
\hline Academic Staff Qualifications & 4.3604 & .81790 & 4 \\
\hline Advice from Teachers & 4.2973 & .89030 & 5 \\
\hline Programs offered & 4.2523 & .79164 & 6 \\
\hline Students' Accommodation & 4.2162 & 1.13942 & 7 \\
\hline Recommendation of Friends and Family & 4.1622 & .99581 & 8 \\
\hline University Environment & 4.1622 & .89990 & 9 \\
\hline Financial assistance & 4.1261 & 1.12910 & 10 \\
\hline Facilities & 4.0450 & 1.01253 & 11 \\
\hline Contact with university Representatives & 4.0090 & .86860 & 12 \\
\hline Tuition fees & 3.9910 & 1.05740 & 13 \\
\hline University Entry Requirement & 3.9820 & .99984 & 15 \\
\hline Contact with Program Representatives & 3.7838 & 1.05663 & 16 \\
\hline Website advertisement & 3.6486 & 1.10904 & 17 \\
\hline Advertisement in Social Media & 3.5405 & 1.07690 & 18 \\
\hline Campus Size & 3.5045 & 1.18225 & 19 \\
\hline University Location near Home & 3.4595 & 1.47577 & 20 \\
\hline Social Activities & 3.3423 & 1.29682 & \\
\hline Advertisement in printed Sources & 3.1892 & 1.17174 & \\
\hline
\end{tabular}

In summary, the above findings provide a comprehensive ranking of the university selection criteria from the students' perspective in the case of Oman. The results provide clear guidelines to the education institutions and authorities in Oman on the main criteria to be enhanced in order to increase students enrolment and success.

\section{Conclusions}

The main purpose of the study was to examine the factors that mostly influence students' selection of the universities where they enrolled, in the Omani context. The study used mean values to rank the factors based on the students' responses. The findings revealed that the main factor for university selection is the university reputation, followed by completion time, academic quality, as well as the academic staff qualifications.

As such, the Omani universities are highly recommended to ameliorate their image as universities offering high quality education. This could be achieved by developing, enhancing and properly implementing their policies and procedures leading to a better standard of learning and teaching for students. The universities are also recommended to ensure that the programs' completion time is not extended longer than expected planned. This could be accomplished among others, by having a proper advising system in place, accompanied by an adequate follow up system. This would allow for example to closely watch the students that are under-probation and provide them with proper advising to enhance their performance in the following semesters. It is noteworthy that many Omani universities have been very successful in implementing innovative advisory systems. This includes for example student to student advising, where junior students are advised and followed up by senior students of the same major. And this has been proven to be a successful and innovative approach of advising. Furthermore, in some other universities, the mere anticipation of students' performance has contributed significantly in reducing the number of students under probation. Hence, the Omani universities are highly recommended to establish new systems to monitor students' performance and avoid having a high percentage of underprobation students.

Even though the current study has brought significant findings and contributions, it still faces some limitations that should be considered in the future studies. Firstly, the sample size is relatively limited 
though accurately calculated. Hence, the future studies are recommended to increase the sample size to cover more respondents. Secondly, the study covered a single setting which is that of Oman, which might not be sufficient to generalize the findings to other similar settings, such as the remaining Gulf countries. Thus, more significant findings are expected if the future studies could cover all the Gulf countries.

Finally, the future studies are recommended to use more developed and enhanced techniques to examine the university selection factors. They are also recommended to use a rather comprehensive and well-established framework.

\section{References}

Agrey, L., \& Lampadan, N. (2014). Determinant factors contributing to students' choice in selecting a university. Journal of Education and Human Development, 3(2), 391-404.

Dahari, Z., \& Abduh, M. (2011). Factors influencing international students' choice towards universities in Malaysia. African Journal of Business Management, 5(26), 10615-10620.

Hair, J.F., Black, W.C., Babin, B.J., \& Anderson, R.E. (2010). Multivariate data analysis, seventh edition. Prentice Hall, Upper saddle river. N. J.

Jafari, P., \& Aliesmaili, A. (2013). Factors influencing the selection of a university by high school students. Journal of Basic and Applied Scientific Research, 3(1), 696-703.

Kruss, G., McGrath, S., Peterson, I., \& Gastrow, M. (2015). Higher education and economic development: The importance of building technological capabilities. International Journal of Educational Development, 43(1), 22-31.

Maniu, I., \& Maniu, G.C. (2014). Educational marketing: Factors influencing the selection of a university. SEA-Practical Application of Science, 3(5), 37-42.

Md. Sidin, S., Hussin, S.R., \& Soon, T.H. (2003). An exploratory study of factors influencing the college choice decision of undergraduate students in Malaysia. Asia Pacific Management Review, 8(3), 259280.

Mehboob, F., Shah, S.M.M., \& Bhutto, N.A. (2012). Factors influencing student's enrollment decisions in selection of higher education institutions (HEI's). Interdisciplinary Journal of Contemporary Research in Business, 4(5), 558-568.

Misran, N., Abd. Aziz, N., Arsad, N., Hussain, H., Wan Zaki, W.M.D., \& Sahuri, S.N.S. (2012). Influencing students for matriculation students in selecting university and program of study. Procedia-Social and Behavioural Sciences, 60(1), 567-574.

Ramalu, J.C.D., Abu Bakar, N., \& Nijar, N.N. (2013). Factors that determine students' preferences in selecting higher learning institution. Infrastructure University Kuala Lumpur Research Journal, 1(1), 27-38.

Winn, P., Leach, L.F., Erwin, S., \& Benedict, L. (2014). Factors that influence student selection of educational leadership Master's programs at regional universities. Administrative Issues Journal: Education Practice and Research, 4(1), 74-86. 